\title{
Pais e responsáveis do adolescente deprimido: buscando conhecer experiências que levaram à procura de atendimento especializado
}

\author{
PARENTS AND CAREGIVERS OF DEPRESSED ADOLESCENTS: LEARNING ABOUT \\ EXPERIENCES THAT LED TO THE SEARCH FOR SPECIALIZED ATTENDANCE
}

\author{
PADRES Y RESPONSABLES DELADOLECENTE DEPRIMIDO: BUSCANDO CONOCER \\ EXPERIENCIAS QUE LLEVARON A LA BUSQUEDA DE TRATAMIENTOS ESPECIALIZADOS
}

\author{
Helmer Magalhães Antunes ${ }^{1}$, Claudinei José Gomes Campos²
}

\begin{abstract}
RESUMO
Este estudo objetivou analisar os processos que levam os pais e responsáveis a perceber a doença depressiva nos filhos adolescentes e compreender a influência das crenças em saúde e dos hábitos culturais na procura de tratamento especializado. Utilizando o método de estudo de caso qualitativo, foram entrevistados quatro pais e responsáveis de adolescentes, com diagnóstico de depressão atendidos em um ambulatório de saúde mental de Campinas. Os dados foram interpretados por análise de conteúdo temático. Segundo os pressupostos teóricos do Modelo de Crenças em Saúde (MCS), foram criadas e discutidas as categorias: a percepção dos pais e responsáveis quanto à suscetibilidade à doença depressiva; a percepção dos pais e responsáveis quanto à severidade da doença depressiva; estímulo externo influenciando a busca de tratamento especializado; as barreiras e benefícios percebidos para busca de atendimento especializado; variáveis estruturais e sociais influenciando na busca de atendimento especializado.
\end{abstract}

\section{DESCRITORES}

Psiquiatria do adolescente.

Cultura.

Educação em saúde.

\begin{abstract}
This study is aimed at analyzing the processes and the motivations that lead parents and caregivers to notice the depressive illness in adolescents and at understanding the influence of health beliefs and cultural habits in the search of specialized treatment. Using the qualitative case study method, four parents and/or caregivers of adolescents with diagnoses of depression under treatment at a mental health clinic in the city of Campinas, State of São Paulo, were interviewed. In accordance with the theoretical presumptions of the Health Belief Model (HBM), the categories that were created and discussed were: the perception of parents and caregivers regarding the susceptibility to the depressive illness; the perception of parents and caregivers regarding the severity of the depressive illness; external stimuli influencing the search for specialized treatment; the barriers and benefits perceived for the search for specialized attendance; structural and social variables influencing the search for specialized attendance.
\end{abstract}

\section{KEY WORDS}

Adolescent psychiatry.

Culture.

Health education.

\section{RESUMEN}

Este estudio tiene como objetivo analisar los procesos y las motivaciones que llevan a los padres y responsables a percibir la adolecencia depresiva en los hijos adolecentes y comprender la influencia de las creencias y de los hábitos culturales en la búsqueda de tratamientos especializados. Utilizando el método de estudio de caso cualitativo, fueron entrevistados 4 padres y responsables de adolescentes con diagnostico de depresión, atendidos en un ambulatorio de salud mental. Según los presupuestos teóricos del Modelo de Crencias en Salud (MCS), fueron creadas las categorías: la percepción de los padres y responsables cuanto a la suceptivilidad de las enfermedades depresivas; la percepción de los padres y responsables cuanto a la severidad de la enfermedad depresiva; estímulo externo influenciando la búsqueda de tratamiento especializado; las barreras y beneficios percibidos para la búsqueda de atendimiento especializado; variables estructurales y sociales influenciando en labúsqueda de atendiemiento especializado.
1 Graduando do $7 .{ }^{\circ}$ semestre do Curso de Graduação em Enfermagem do Depto. Enf.-FCMUNICAMP. Bolsista FAPESP - Iniciação Científica.

2 Enfermeiro. Doutor em Ciências Médicas/Saúde Mental. Professor Colaborador do Depto. Enf.-FCMUNICAMP. Membro do Núcleo de Pesquisa em Psicanálise, Enfermagem e Saúde Mental (NUPPESM) do Depto. Enf-FCMUNICAMP. cjcampos@ fcm.unicamp.br

\section{DESCRIPTORES}

Psiquiatría del adolescente.

Cultura.

Educación en salud. 


\section{INTRODUÇÃO}

A ocorrência de depressão em adolescentes tem se tornado freqüente em nosso meio. A não aceitação da veracidade de tal fato, no decorrer da história, se configurou em um incrível obstáculo no que diz respeito à definição do problema do paciente e no concomitante tratamento adequado $^{(1)}$. De tal forma podemos levar em consideração que por muito tempo tal idéia foi sendo introjetada pela população e acrescentada à cultura, o que poderia contribuir significantemente para a não atribuição de importância para os sintomas depressivos notados. A cultura como um saber pessoal e o conjunto de valores de uma sociedade ${ }^{(2)}$, guarda para si uma maneira peculiar de visualizar pensamentos e comportamentos.

A percepção dos fenômenos patológicos, portanto, está intimamente ligada aos fenômenos sociais e culturais apreendidos no decorrer da história e que modificam as técnicas de intervenção sobre eles ${ }^{(3)}$. Para conhecer as motivações de busca de atendimento especializado para depressão em adolescentes temos, portanto, que nos reportar a tais crenças culturais.

Sintomas que hoje fazem parte dos manuais diagnósticos como humor deprimido ou irritável; interesse ou prazer acentuadamente diminuídos, perda do ganho significativo de peso ou diminuição ou aumento do apetite, insônia ou hipersônia, ideação suicida, tentativa ou plano suicida, entre outros classificados $^{(4)}$, são percebidos pelos indivíduos leigos, segundo seus referenciais empíricos, os quais vão se agregando ao seu corpo de percepções e conhecimentos acerca dos males e práticas de saúde ao longo de sua existência.

Os adolescentes, muitas vezes, apresentam sintomas depressivos que são considerados apenas como "alterações do comportamento"(5), ou seja 'próprio da idade', fazendo com que os pais não dêem credibilidade a essas manifestações.

Em relação à busca de atendimento especializado, segundo pesquisas nos EUA em 1974, dos pacientes deprimidos, 2/3 não procuravam ajuda médica, $1 / 3$ procurava por ajuda de um clínico geral e $1 / 6$ por um psiquiatra. Dos $2 / 3$ que não procuram atendimento médico, existe a parcela que procura se tratar levando em consideração um diagnóstico de manifestações anímicas, buscando cura por práticas religiosas e mágicas, e os que fazem um diagnóstico de causas externas, buscando ajuda com yogas, ginásticas e alimentação natural ${ }^{(6)}$.

No Brasil, em termos de primeira ajuda, procura-se um clínico geral ou um médico de especialidade não psiquiátrica, ou ainda um psicólogo ou um psicanalista com vista à realização de uma psicoterapia ${ }^{(6)}$. A procura de um clínico geral, em vez de um psiquiatra, pode demonstrar-nos que a doença psiquiátrica é, por vezes, associada a algum sintoma físico; mas pode simplesmente significar um não conhecimento do psiquiatra e seu papel.
A grande concentração de adolescentes no país e a expectativa de que em 2020, segundo a Disability Adjuste Life Years, a depressão maior será a segunda principal patologia geradora de sobrecarga sobre os serviços de saúde ${ }^{(7)}$, somados às necessidades citadas anteriormente, remete- nos à importância de se iniciar rapidamente o tratamento do adolescente deprimido.

Se, por um lado, para que ocorra o rápido tratamento é necessária a conscientização da população acerca dos principais sintomas depressivos e acerca da suscetibilidade de adolescentes à depressão, por outro é necessário compreender as crenças que as pessoas têm em relação à depressão e seu tratamento por profissionais especializados. Sendo a família um alicerce que tem um valor em si mesmo e seu apoio é decisivo tanto na afetividade dispensada ao doente, como na busca e acompanhamento do tratamento ${ }^{(8)}$, deve-se, por meio da educação em saúde, desmistificar e capacitar minimamente os pais e responsáveis dos jovens a reconhecerem, precocemente, sinais ou comportamentos indicativos de um quadro depressivo, levando-se em consideração os seus próprios referenciais empíricos.

\section{REFERENCIAL TEÓRICO}

Tomamos os pressupostos teóricos do Modelo de Crenças em Saúde (M.C.S.), como modelo para embasar nossas discussões neste trabalho.

Nascido primeiramente com o objetivo de explicar o por quê das pessoas não se prevenirem corretamente contra doenças para as quais já havia testes e vacinas, o M.C.S., conforme suas observações, tenta explicar (especificar) as variáveis de tais comportamentos ${ }^{(9)}$.

O M.C.S. parte do pressuposto básico que um indivíduo emite comportamentos preventivos em relação a uma doença ${ }^{(10)}$ acreditando: que ele é pessoalmente suscetível a ela; que a ocorrência da doença deverá ter pelo menos moderada seriedade em algum componente de sua vida; que, tomando uma ação particular, esta deveria, de fato, lhe ser benéfica reduzindo sua susceptibilidade, ou se a doença ocorreu, reduzindo sua seriedade, e que haja barreiras psicológicas importantes, tais como custo, conveniência, dor, embaraço, entre outras.

Além dessas dimensões, fazem parte do M.C.S. alguns estímulos que eliciam o processo de tomada de decisão, que podem ter origem interna (por exemplo um sintoma) ou externa (influência da família, dos amigos, dos meios de comunicação etc) $)^{(9)}$.

É importante ressaltar que o M.C.S é um referencial utilizado basicamente em pesquisas quantitativas. Neste estudo, entretanto, utilizamos apenas os seus pressupostos teóricos, adaptando-o assim à nossa necessidade. 


\section{OBJETIVOS}

Analisar os processos e as motivações que levaram os pais e responsáveis a perceberem a doença depressiva nos filhos adolescentes e à conseqüente procura de cuidado especializado;

Compreender a influência das crenças em saúde e dos hábitos culturais na procura de tratamento da doença depressiva em adolescentes.

\section{MÉTODO}

Optamos pelo método qualitativo, especificamente o estudo de caso, para realização da pesquisa. Estudos de casos qualitativos visam a descoberta, fazendo com que o pesquisador não se atenha somente a pressupostos, mas também a novos elementos durante o estudo.

A multiplicidade de dimensões presente em uma determinada situação pode também ser focalizada pelo estudo de caso levando à não apreensão ao problema focalizado. Pode-se usar diferentes fontes de informações buscando incidir naquilo que ele tem de único, mesmo que posteriormente venham ficar evidentes certas semelhanças com outros casos ou situações ${ }^{(11)}$.

O local escolhido para a pesquisa foi o ambulatório de psiquiatria do Hospital das Clínicas da UNICAMP, que atende pacientes na área de saúde mental da região de cobertura de Campinas.

Os sujeitos de nossa pesquisa foram os pais ou responsáveis pelo adolescente que tem diagnóstico de depressão. A amostra, que contou com quatro indivíduos (três mães de adolescente e um pai), foi selecionada intencionalmente, segundo a capacidade dos informantes em fornecer dados relevantes para o alcance dos objetivos da pesquisa $^{(12)}$. A inclusão de novos sujeitos findou quando as informações começaram a se repetir com alguma freqüência, segundo a técnica de saturação de dados.

Os pesquisadores apresentaram a cada entrevistado um termo de Consentimento Livre e Esclarecido respeitando os direitos do indivíduo de participar voluntariamente após serem informados acerca dos procedimentos da pesquisa. O projeto foi aprovado pelo Comitê de Ética em Pesquisa (CEP) da Faculdade de Ciências Médicas da UNICAMP.

Para a realização da pesquisa utilizamo-nos de um roteiro de entrevistas, contendo perguntas relacionadas aos dados socioculturais da população estudada, as percepções sobre os profissionais da área de saúde mental, motivações que o levaram a buscar auxílio especializado para o familiar adoecido e sua experiência em lidar com problemas de saúde acontecidos anteriormente. Escolhemos a entrevista semi-estruturada pela possibilidade de se estabelecer com o entrevistado a liberdade e espontaneidade necessárias para o enriquecimento da investigação sem, entretanto, desvincular-se do objetivos propostos anteriormente, de acordo com informações, propósitos e interrogativas previamente elaboradas pelo investiga$\operatorname{dor}^{(13)}$.

Optamos pelo método de análise de conteúdo como forma de analisar os dados, já que este nos dá liberdade para realização de inferências e nos proporciona compreensão dos diversos significados contidos nas entrevistas. Neste processo foram seguidas as seguintes fases: fase pré-exploratória do material (leituras flutuantes das entrevistas); seleção das unidades de análise e codificação; processo de categorização, entendendo as categorias como enunciados que podem abranger um número variável de temas, segundo seu grau de intimidade ou proximidade ${ }^{(14)}$. As categorias foram enunciadas a priori, seguindo o referencial teórico do M.C.S.

\section{ANÁLISE E DISCUSSÃO DOS DADOS}

\section{Caracterização sociocultural dos sujeitos da pesquisa:}

Obtivemos, em nossa amostra, indivíduos com idades que variaram entre trinta e três (33) a quarenta e oito (48) anos, com média de 42 anos. A variação do grau de instrução foi desde o sujeito sem instrução formal declarada até aquele com ensino superior completo. Todos os entrevistados declararam-se participantes da renda da casa exceto o que tinha curso superior completo (aposentada). A religião também se mostrou presente nas famílias dos adolescentes deprimidos: dois deles se declararam evangélicos e dois católicos. Um dos entrevistados diz ter se tornado evangélico após o início dos problemas com seu filho adolescente.

\section{Apresentação das categorias e discussão dos temas obtidos:}

\section{A percepção dos pais e responsáveis quanto à suscetibilidade à doença depressiva}

O M.C.S. nos mostra que, em relação à suscetibilidade percebida, as pessoas variam muito quanto à aceitação da possibilidade de contrair uma determinada condição. Num extremo, poderemos ter indivíduos que negam qualquer possibilidade de contrair uma dada condição, em segundo podemos ver os que podem admitir a possibilidade, mas que essa seja improvável e, finalmente, veremos os que podem realmente expressar a possibilidade real de estar em perigo quanto à doença ${ }^{(10)}$. Tal percepção individual poderá influenciar positivamente ou negativamente a busca por tratamento. 
A percepção da susceptibilidade pode ser um evento inconsciente e pode adquirir formas sólidas em momentos posteriores (por exemplo, após o início de tratamento), como vemos abaixo:

\section{(...) o problema dele não era a maconha, o problema dele era a família. E minha família já tem um problema sério de depressão, e também tem o desemprego do meu marido, eu... enfartei... e juntou o desemprego, nós tínhamos um poder aquisitivo legal, a mudança de São Paulo pra cá, meu marido veio pra cá, aí a Transbrasil faliu, aí, esse monte de problema contribuiu... eu, meu marido desincentivado, eu desincentivada, e tudo isso dá o efeito no meu filho. (e4)}

Nesse caso a mãe conseguiu ligar os acontecimentos e apontar a instabilidade familiar como fator desencadeante do problema depressivo do filho. Esse fato é relevante à medida em que se pode afirmar que existe a percepção, mesmo que empírica, por parte de alguns indivíduos, da existência de uma multicausalidade gerando doenças mentais e também a importância que os fatores psicossociais, neste caso específico, uma desestruturação familiar por problemas socioeconômicos, podem ter no desenvolvimento destas doenças.

Mesmo não sendo esse o evento principal para procura de tratamento, neste caso é importante notar como se constroem tais percepções.

Em outro caso o mesmo processo é observado no relato de um sujeito da pesquisa em relação ao adolescente deprimido que apresenta diabetes:

\footnotetext{
Porque se você for pensar não é normal. Porque você pode comer o tanto que você quer e você come e não tem fome... e quando você tem aquela vontade de comer, você come até passar a vontade. E tudo na vida dela é, não. Comer doce: não; ela queria repetir prato e: não... aí sabe... tudo isso eu acho que vai bloqueando, não é? Bloqueando a pessoa... não é normal. (e3)
}

A percepção do problema da diabetes como causador de frustração, aborrecimento e tristeza no adolescente é claramente expresso nesse trecho. Entretanto, como o exemplo acima, a mãe não utilizou tal percepção inconsciente para iniciar a busca por atendimento, mas com certeza esse foi um fator influenciador.

A negação da suscetibilidade à doença também pode ser notada em uma das entrevistas:

Mas adolescente eu não sei... que nem no caso dela... não falta nada... tem tudo, aí eu não sei. Aí que não dá pra entender né? (e1)

Neste caso, as diversas restrições e dificuldades familiares no que diz respeito às posses e aos ganhos materiais, acabam influenciando no surgimento da idéia de que a depressão está simplesmente ligada a isso. Estar deprimido é estar com "falta das coisas em casa". O fato de "não lhe faltar nada"elimina a possibilidade da paciente ser suscetível a algum problema podendo influenciar negativamente na procura por atendimento especializado. Essa visão materialista encontra fortes raízes na cultura ocidental, onde o sucesso econômico e o bem-estar físico e mental estão associados de uma maneira quase mágica, criando nas pessoas a falsa segurança de que a suscetibilidade a determinadas doenças está intrinsecamente associada a privações materiais.

Pode-se definir a severidade como a gravidade ou seriedade da doença que pode ser avaliada tanto pelo grau de perturbação emocional criado ao pensar na doença quanto pelos tipos de conseqüências que a doença pode acarretar (dor, morte, gasto material, interrupção de atividades, perturbações nas relações familiares e sociais) $)^{(9)}$.

A percepção da seriedade de determinado sintoma por vezes é o principal desencadeador da busca por atendimento especializado com o objetivo de se minimizar as perdas devido à situação de estresse provocada. A perturbação das relações familiares normais ocasionadas pela agressividade, uso de drogas e 'nervosismo' foram pontos importantes para que ocorresse a busca de tratamento:

\begin{abstract}
(...) eu ia atrás e brigava porque eu tinha sempre muito medo de droga. Com isso ele começou a decair na escola, até o dia que eu o peguei (eu lutei muito pra pegar), aí eu peguei e ele ficou muito decepcionado e não conseguia me encarar e depois disso ele começou a ficar agressivo e num desses ataques dele de raiva e agressividade nós trouxemos ele no pronto socorro da UNICAMP. (e4)
\end{abstract}

(...) É que ela era... muito nervosa... ahnnn... Nadinha que a gente conversava ela ficava nervosa e já ia xingando... ficava já brigando... Aí a mãe dela procurou... o médico e falou que ela tava muito nervosa. (e1)

É importante ressaltar que sinais como a agressividade, além de outros decorrentes do uso de substâncias psicoativas, sinalizam situações de ameaça à própria vida do adolescente, bem como a integridade física dos outros indivíduos relacionados a ele, concorrendo desta maneira, para uma percepção mais emergencial de cuidados especializados. Outro fato também ameaçador e até mais chocante são as tentativas de suicídio como eventos perturbadores da relação familiar que também são considerados como causa da busca de atendimento:

\section{(...) O que me incomodou mais foi quando eu cheguei do serviço e o menino tinha me falado que ela tinha tentado se enforcar com a própria blusa. Aí né... o que eu suspeitava, eu acabei concluindo... aí eu levei ela, no postinho, centro de saúde... e eles me mandaram pra cá. (e2) \\ (...) não precisava de mais nada. Aí depois que ela tentou suicídio é que eu trouxe ela. (e2)}

Apenas quatro por cento dos pacientes deprimidos estão em tratamento por ocorrência de idéias suicidas. Em números gerais, uma quantidade significativa de pessoas está corren-

www.ee.usp.br/reeusp/ 
do risco potencial em tentativas de suicídio $^{(6)}$. Considerando a gravidade de tal evento, é importante se tomar os devidos cuidados na assistência a tais casos já que a sua existência pode levar a êxito fatal. Esse é um sintoma importante para o diagnóstico de depressão e é necessária a tentativa de se notar precocemente sinais ou evidências que o adolescente possa estar com tal tipo de ideação.

A severidade da doença é percebida também quando ocorre interrupção das atividades cotidianas do adolescente como, por exemplo, a realização de atividades antes prazerosas:

\begin{abstract}
Antes ela tava muito assim, isolada, não aceitava carinho, não aceitava brinquedo nenhum né. $E$ se isolava, ficava o dia inteiro no quarto escuro, fechava a cortina, fechava a porta, ficava lá só escutando música, levantava só pra tomar água... tomar água. (e2)
\end{abstract}

Humor deprimido, interesse ou prazer acentuadamente diminuídos, capacidade diminuída de pensar ou concentrarse, sintomas clássicos dos quadros depressivos ${ }^{(4)}$, podem ser percebidos pelos pais de acordo com a significação individual que cada um atribui a esses fenômenos. Por meio de tais percepções ocorre a assimilação dos sintomas científicos da depressão, incorporando-o ao seu universo cultural, mesmo que de forma empírica.

A assimilação pelas classes populares dos conhecimentos médicos de origem científica e sua interação no corpo de conhecimentos de classe só é possível através de toda uma série de transformações, que tem como conseqüência desbaratar o empréstimo dos conceitos médicos e mesmo desnaturá-los ${ }^{(15)}$.

\section{Estímulo externo influenciando a busca de tratamento especializado}

O modelo de crenças ainda ressalta que existem estímulos que influenciam o processo de tomada de decisão funcionando como fatores modificadores da ação sobre a ameaça percebida de determinada doença. Tais estímulos relacionam-se a conselhos de terceiros, lembretes escritos de profissionais de saúde, de experiências de membros da família, bem como outros meios de informação ${ }^{(10)}$.

Em nossas entrevistas encontramos exemplos da ação direta de profissionais tanto da saúde, como de educadores, agindo no sentido de influenciar positivamente na procura de atendimento especializado, como podemos observar abaixo:

E eu só fui perceber isso agora, meu marido era contra a terapia. No colégio que ele estava a orientadora já havia me falado o ano passado: Sozinho ele não vai dar conta, ele precisa de uma psicoterapia. (e4)

Mas na verdade eu descobri que ele tava com depressão aqui, há dois meses atrás, por causa da Dra. Y que já diagnosticou, e foi aí que eu comecei a me ligar porque apesar de ser psicóloga... de ter estudado isso, de ter Ihe dado com isso, mas pelo fato de ser meu filho então... (e4)
Percebemos nesta última fala, como o envolvimento afetivo existente entre os membros da família, pode levar, até mesmo pessoas teoricamente capacitadas em detectar a doença, caso da psicóloga e mãe do adolescente, à não percepção da patologia.

A doença mental traz ainda questões históricas atreladas a si que a tornam extremamente estigmatizada, despertando muitas vezes mecanismos de negação nas pessoas, prejudicando desta maneira a procura do médico especialista. Tal afirmação pode nos levar a inferir a existência de uma porção significativa de adolescentes que esteja sem tratamento adequado, devido a não associação de seus sintomas com o diagnóstico de depressão ${ }^{(16)}$.

É interessante notar, que a experiência dos pais não se passa, entretanto, apenas com profissionais da área da saúde. A presença de educadores, assistentes sociais, dentre outros, pode ser de extrema importância para desenvolver nos pais e responsáveis pelo adolescente uma visão mais realista acerca da necessidade de uma percepção mais precoce de doenças importantes como a depressão. Contudo, vê-se a importância da atuação conjunta dos profissionais da área da saúde, principalmente dos enfermeiros, como agentes de formulação de práticas educativas em saúde, em conjunto com outros profissionais ou mesmo com os próprios pais, para o esclarecimento acerca da depressão. A assistência da enfermagem não se limita apenas em ajudar o paciente, mas também em orientar a família e a comunidade ${ }^{(16)}$.

A experiência prévia similar com amigos ou conhecidos também tem importância nas experiências dos pais, servindo como estímulo externo para o reconhecimento da doença depressiva e conseqüente busca de atendimento:

\footnotetext{
E tem assim: lá no serviço tem um moço que mora lá que ele é bem assim. Ele é bem assim depressivo. E eu tinha uma imagem assim, talvez por ele, que não tem amizade, não tem colega nenhum, é uma pessoa isolada, uma pessoa brigada com os pais sabe, que nada ta bom. E passava muito tempo trancado no quarto e falavam: ele ta muito depressivo e eu escutava - depressão. E ... quando ela começou a ficar desse jeito daí eu falei, não... ela deve estar com depressão. (e2)
}

Os tratamentos passam por toda uma "rede terapêutica", iniciada pelos conselhos da família, amigos, vizinhos e passando aos curandeiros populares ou aos médicos. $\mathrm{O}$ aprendizado oferecido através de cada etapa passa a fazer parte dos conhecimentos e crenças que podem ou não ser aceitos pela pessoa ${ }^{(17)}$. Os conhecimentos leigos obtidos através de experiências anteriores na observação de outros indivíduos puderam direcionar a tomada de decisão acerca do ser ou não depressivo.

Tal alternativa de busca de conhecimentos de saúde ou mesmo de assistência à saúde através de amigos e conhecidos é chamada de assistência informal, existindo três alter- 
nativas de busca de assistência à saúde: a informal, a popular e a profissional ${ }^{(17)}$. Duas delas puderam ser notadas por nós de acordo com os exemplos acima: a informal e a profissional.

O setor informal é o campo leigo, não-profissional e nãoespecializado da sociedade, onde as doenças são em primeiro lugar reconhecidas e definidas, para posteriormente serem iniciadas as atividades de tratamento. O setor profissional compreende profissões sindicalizadas e sancionadas legalmente, como a medicina científica ocidental ou alopatia. As experiências vividas através dessas alternativas de assistência podem ajudar na formação dos significados, como vimos nos exemplos acima. Por vezes, tais experiências leigas e estímulos externos levam os pais do adolescente deprimido a não buscar atendimento especializado:

E a gente ia ver sozinho né... talvez com o tempo passasse não é? Mas não era... quanto mais o tempo passava pior ia ficando. (e1)

Muitas vezes os motivos da não procura de auxílio especializado estão ligados ao não convencimento por parte dos pais ou responsáveis da severidade da doença, acreditando como vimos, na sua remissão espontânea. Outro motivo, este relacionado à própria natureza e compreensão leiga das doenças mentais, é a aceitação do fato de que possa existir dentro da família um indivíduo com tal doença, ou seja, a admissão para a sociedade da presença de um doente mental na família. Dessa forma cria-se uma situação embaraçosa e estigmatizante no seio familiar. Percebemos que esta última motivação quando não detectada ou esclarecida no sentido de desmistificar a doença mental, pode acarretar prejuízos e desestruturação maiores ao doente e à própria família. Outra situação é a procura de ajuda não profissional, estimulada por influências culturais, como vemos a seguir:

Ah.... é mesmo... isso mesmo. A mãe dela chegou a procurar uma benzedorinha.... Num deu nada. A benzedora fa-

lou que ela não... não tinha nada desse tipo de coisa. (e1)

A própria busca pelo curandeiro (ou benzedeira) demonstra que existem méritos para isso, sendo um deles a explicação ao doente do que realmente ele sofre. Além disso, o curandeiro utiliza uma linguagem imediatamente acessível aos membros das classes populares e fornece explicações que contêm representações da doença que despertam alguma coisa no espírito dos membros de classes menos favorecidas ${ }^{(15)}$. Entretanto, a cura pela sugestão, na maioria das vezes, é ineficaz, fazendo com que a pessoa redirecione sua busca à medicina tradicional.

As barreiras e beneficios percebidos para busca de atendimento especializado

O M.C.S. define ainda que a suscetibilidade e a severidade percebidas podem conduzir à tomada de uma ação, mas não definem a ação que será tomada. A ação dependerá das crenças que o indivíduo tem em relação à efetividade das alternativas conhecidas para tomada de decisão. Seu comportamento dependerá, então, da crença do quão benéficas, para o seu caso, serão as várias alternativas para reduzir a ameaça a cada condição de saúde ${ }^{(10)}$.

Os benefícios percebidos referem-se à crença na efetividade da ação e à percepção de suas conseqüências positivas; e as barreiras percebidas referem-se aos aspectos negativos da ação, que são avaliados em uma análise tipo custo-benefício, considerando possíveis custos de tempo, dinheiro, esforço, aborrecimentos ${ }^{(9)}$. Algumas barreiras foram facilmente observadas:

... porque ele fazia coisas desde pequeno assim, um dia ele chegou e falou assim: mãe, eu vou enfiar uma faca no meu coração, eu quero morrer!... Então a gente achava engraçado, e falava: Nossa $X$ que é isso??? E a gente achava normal, que ele ficava assistindo muito assim, desenhos... não é? E ele é muito bonito assim, é loirinho, cabecinha branca, olho azul, bonitinho, lindo, lindo...e eu achava que ele nunca ia ter problema no mundo (...). (e4)

Nesse caso a mãe do adolescente relata uma ocasião em que seu filho queria se matar, mas tudo era encarado como uma brincadeira normal para uma criança dessa idade e que, talvez, estivesse impressionada com alguns desenhos violentos. Pensar que o filho tão novo possa estar falando com seriedade em se matar poderia ser prerrogativa de muito problema e transtorno para a família. Nesse caso a somatória das barreiras contra uma ação efetiva são maiores do que os benefícios e a tentativa de negar o problema que causará ameaça social, pelo menos momentaneamente, é mais bem aceita.

Neste recorte, ainda se observa a idealização da aparência física como uma prerrogativa importante para o reconhecimento do ser saudável, sendo que no caso das doenças ditas mentais, muito mais que a aparência física, a percepção de sinais emocionais, altamente relevantes, são muitas vezes relegados a um segundo plano.

Outras barreiras, como a financeira, são relatadas por nossos sujeitos de pesquisa:

\section{(...) Eu já queria mandá-lo para a terapia mas meu marido}

não queria. Aquele problema financeiro (não gastar). (e4)

O problema financeiro é relatado nesse caso como um incentivador negativo (barreira) para a busca de tratamento especializado. Tal fato pode ser entendido, pois nos últimos anos uma clara evolução no tocante ao tratamento medicamentoso da depressão (hoje medicações que inibem a recaptação da serotonina são largamente utilizados com bons resultados), bem como do oferecimento de serviços de psicoterapia. Entretanto, tais terapêuticas acabam por ser inviáveis para indivíduos de classes menos favorecidas, devido ao seu alto preço, o que resulta, na maioria das vezes, em um tratamento impossível para quem não tem acesso a um serviço público de referência. 
A elaboração da crença pessoal de que o serviço especializado é o melhor lugar para atender o adolescente com problemas se mostrou como benefício percebido para a busca e superou as barreiras, como no caso relatado abaixo:

Eu achei que podia ser uma coisa assim... que na idade dela, precisa de ajuda. Eu acho que qualquer um precisa de ajuda... eu preciso de ajuda. E essa coisa você procura com as pessoas que têm mais experiência, que sabe mais que você, entende, que vai te ajudar, que você confia... (e3)

Variáveis estruturais e sociais influenciando na busca de atendimento especializado

Existem ainda, segundo o M.C.S, fatores modificadores da percepção individual e que influenciam indiretamente na ação final como variáveis psicossociais (personalidade, classe social, pressão social) e estruturais (conhecimento sobre a doença, contato anterior com a doença $)^{(9)}$.

No que diz respeito às variáveis sociais chamou-nos atenção um aspecto cultural muito importante: a visão da loucura e sua ligação com o psiquiatra e o tratamento psiquiátrico:

Mas também eu sou bastante resistente à internação psiquiátrica. Então, pelo que a gente vê até em filmes não é? Que hospital psiquiátrico judia, dopa (...) Mas eu sou completamente preconceituosa quanto á psiquiatria, na questão de choque (...) (e4)

O conhecimento popular e a crença na loucura foram fatores sócio-culturais importantes nesses casos e que influenciaram significantemente na tomada de decisões. A condição de depressivo e de ser paciente de um psiquiatra ou passar por tratamento psiquiátrico levam em si um estigma popular de fundo histórico. O surgimento das instituições psiquiátricas (hospitais psiquiátricos e manicômios) e da internação psiquiátrica em moldes não muito humanitários na antigüidade, levou à ligação da psiquiatria com perigo, medo e caos. Em sua grande maioria tais locais eram usados para isolar a pessoa, incapacitá-la de conviver com os normais e vigiar suas atividades a fim de não oferecer perigo a si mesmo e aos outros ${ }^{(18)}$.

Essa autora ainda ressalta que não se romperam os 'verdadeiros grilhões' das antigas práticas de internação dos loucos, mas elas parecem ter se estreitado em torno dos doentes mentais. As pessoas têm diversas atitudes a respeito do que seja a doença mental, expectativa referente ao comportamento das pessoas "mentalmente doentes" e algumas idéias sobre como os doentes mentais devem ser tratados. Ainda afirma que essas atitudes estão diretamente relacionadas às crenças culturais.

O doente mental perde, para a sociedade à qual pertence, a sua condição de sujeito, no sentido etimológico do termo, sub-jectum, aquele que subjaz às ações, às enunciações do discurso. Desde o instante em que a marca da loucura lhe foi imputada, é como se no lugar do sujeito aparecesse a doença mental. Então, o discurso e as ações expressos pelo doente cessam de significar em si próprias, tornando-se apenas sintomas da doençca ${ }^{(19)}$.

Diante disso, é conseqüente inferir que ocorre uma ligação inconsciente: depressão-psiquiatra-loucura, sendo isto parte de uma herança cultural e formadora de crenças próprias de cada pessoa podendo influenciar negativamente na busca de atendimento especializado.

\section{CONSIDERAÇÕES FINAIS}

Percebemos dificuldades dos pais dos adolescentes deprimidos relacionarem os sintomas percebidos com a depressão. A dificuldade de se fazer tal associação é, por vezes, tão individual que mesmo pais que teriam, teoricamente, capacidade clara de reconhecer os sintomas depressivos (pai psicólogo) não o fizeram. Por vezes, o reconhecimento ocorreu de forma mais tranqüila e eficaz, sendo que o pai, utilizando sua percepção e subjetividade, pôde proporcionar um início mais rápido do tratamento.

Entretanto a percepção não tem sido tão rápida algumas vezes fazendo com que o adolescente passe por episódios (tentativas de suicídio e crises de agressividade) que poderiam ser evitados com um tratamento precoce, melhorando a qualidade de vida do adolescente, contribuindo para o restabelecimento da normalidade e, conseqüentemente, da melhoria do prognóstico da depressão.

A existência das crenças em saúde e crenças culturais, mostra-se altamente modificadoras da percepção individual da doença depressiva e da conseqüente busca de tratamento especializado. Fatores pessoais como experiências prévias com a doença, contato com profissionais da saúde e outros foram alguns destes agentes. Fatores socioculturais como a visão positiva sobre a psiquiatria e a doença mental, também se mostraram modificadores de conduta.

Reconhecemos o modelo médico-assistencial privativista, ainda hegemônico no país, comprovadamente um modelo de 'mão única' por atender somente a demanda espontânea ${ }^{(20)}$. Ainda que importante, carece de um movimento de educação em saúde, fato que já vem ocorrendo com a adoção do modelo de promoção da saúde, com programas como o de Saúde da Família, que facilitam o acesso à informação, visto que atende a família como um todo, na própria comunidade e pode desenvolver no trabalho direto com os pais. Acreditamos que neste programa possa ser incluído um trabalho de educação e conscientização em relação à possibilidade de ocorrência das doenças mentais em adolescentes, melhorando o acesso a informações e serviços, facilitando assim a percepção dos pais e responsáveis pelo adolescente, no tocante à descoberta da doença e a busca mais precoce por atendimento para seus filhos. 
O treinamento de profissionais da área de saúde (todas as áreas) e principalmente os profissionais de enfermagem que estão mais próximos ao paciente e família, para fornecer informações específicas, também é fato importante. Acreditamos que um trabalho educativo realizado em conjunto com os diversos seguimentos da sociedade e o

\section{REFERÊNCIAS}

1. Versiani M, Reis R, Figueira I. Diagnóstico do transtorno depressivo na infância e adolescência. J Bras Psiquiatr. 2000;49(10/12):367-82.

2. Bueno FS. Minidicionário da língua portuguesa. São Paulo: FDT; 2000

3. Montero P. Da doença à desordem: a magia na Umbanda. Rio de Janeiro: Graal; 1985.

4. Jorge MR, coordenador. Manual diagnóstico e estatístico de transtornos mentais. Trad. de Dayse Batista. $4^{\mathrm{a}}$ ed. Porto Alegre: Artmed; 2002.

5. Soares KVS. Sintomas depressivos em adolescentes e adultos jovens: análise dos dados do estudo multicêntrico de morbidade psiquiátrica em áreas metropolitanas [tese]. Campinas: Universidade Estadual de Campinas; 1993.

6. Paproki J. O atendimento e a trajetória habitual do paciente deprimido. Arq Bras Med. 1992;66(3):220-5.

7. Bahls SC. Aspectos clínicos da depressão em crianças e adolescentes. J Pediatr. 2002;78(5):359-66.

8. Osinaga VLM, Vieira MJ, Armelin MVAL, Furegato ARF. Trabalhando com histórias de vida de familiares de pacientes psiquiátricos. Rev Esc Enferm USP. 2000;34(4):401-6.

9. Coleta MFD. O modelo de crenças em saúde: uma aplicação a comportamentos de prevenção e controle da doença cardiovascular [tese]. Brasília: Universidade de Brasília; 1995.

10. Lescura Y, Mamed MV. Educação em saúde: abordagem para o enfermeiro. São Paulo: Sarvier; 1990. mais próximo possível da comunidade possa criar novas perspectivas e possibilidades de uma maior abrangência de disseminação de conhecimentos básicos à população, para a percepção dos sinais e sintomas da depressão, doença que tem tido importante aumento de incidência no passar dos anos, sobretudo na população adolescente.

11. Ludke M, André MEDA. Pesquisa qualitativa em educação: abordagens qualitativas. São Paulo: EPU; 1986.

12. Campos CJG. A vivência do doente renal crônico em hemodiálise: significados atribuídos pelos pacientes [tese]. Campinas: Universidade Estadual de Campinas; 2002.

13. Bogdan RC, Biklen SK. Investigação qualitativa em educação. Porto: Porto Editora; 1994.

14. Campos CJG. O método de análise do conteúdo: ferramenta de análise de dados qualitativos no campo da saúde. Rev Bras Enferm. 2004;57(5):611-4.

15. Boltanski L. As classes sociais e o corpo. $3^{\mathrm{a}}$ ed. Rio de Janeiro: Graal; 1989.

16. Silva MCF, Furegato ARF, Costa Junior RLC. Depressão: pontos de vista e conhecimento de enfermeiros da rede básica de saúde. Rev Lat Am Enferm. 2003;11(1):7-13.

17. Helman CG. Cultura, saúde e doença. $2^{\mathrm{a}}$ ed. Porto Alegre: Artes Médicas; 1994.

18. Humerez DC. Enfermagem e loucura: visão do conceito de loucura e do ser louco no cotidiano da instituição manicomial e os reflexos na prática de enfermagem [dissertação]. São Paulo: Escola de Enfermagem, Universidade de São Paulo; 1988.

19. Naffah Neto A. O estigma da loucura e a perda da autonomia. Bioética. 1998;6(1):81-7.

20. Paim JS. A reforma sanitária e os modelos assistenciais. In: Rouquayrol MZ, Almeida Filho, N. Epidemiologia e saúde. $5^{\text {a }}$ ed. Rio de Janeiro: MEDSI; 1999. p. 473-87. 